\title{
Sobre la identidad del «físico» citado en la col. IV del papiro de Derveni ${ }^{1}$
}

\author{
Carlos Megino \\ Universidad Autónoma de Madrid \\ carlos.megino@uam.es \\ On the identity of the physikós quoted in col. IV \\ of Derveni papyrus
}

\begin{abstract}
Se intenta establecer qué filósofo o, en su defecto, movimiento filosófico, satisface la doctrina sobre la plegaria y el azar que el comentarista del papiro de Derveni atribuye al «físico» que cita en la col. IV, de modo que pueda ser con cierta probabilidad el objeto de la cita. En este contexto, se discute la posibilidad, defendida por Ferrari, de que pudiera tratarse de Demócrito, ofreciéndose argumentos complementarios a favor de esa hipótesis.
\end{abstract}

Palabras clave: Demócrito; Papiro de Derveni; plegaria; azar; mal; Heráclito.
I try to establish who is the philosopher or, if he is not found, the philosophical movement, who satisfies the doctrine about prayer and chance, that the Derveni papyrus' author attributes to the "physicus» quoted in column IV, so that this philosopher can probably be identified with this physicus. In this context, I discuss the possibility, defended by Ferrari, of the physicus in question being Democritus, and I give complementary arguments in favor of this hypothesis.

Keywords: Democritus; Derveni Papyrus; prayer; chance; evil; Heraclitus.

${ }^{1}$ Un primer esbozo de este trabajo fue presentado en las IV Jornadas de Papirología: 50 años del descubrimiento del Papiro de Derveni, que tuvo lugar en la Universidad de Salamanca entre el 17 y el 19 de mayo de 2012. Este estudio se enmarca en el Proyecto de Investigación Estudios sobre la transposición de la doctrina órfica en la filosofia estoica, con referencia FFI2009-08162, financiado por la Dirección General de Investigación del Ministerio de Ciencia e Innovación. 


\section{INTRODUCCIÓN}

La nueva reconstrucción de la col. IV del Papiro de Derveni debida a las integraciones de F. Ferrari al texto ${ }^{2}$, presenta a un «físico» $(\varphi v] \sigma ! ̣ \leqslant[o ́ \varsigma)^{3}$ al que el autor del papiro atribuye una doctrina sobre la plegaria y el azar que ha planteado algunos problemas de interpretación. Entre ellos, el del acuerdo o no del autor del papiro con dicha doctrina, la concordancia o no de ésta con la cita de Heráclito en la misma columna y, finalmente, el de la identidad del físico en cuestión.

Me he ocupado de los dos primeros problemas en un trabajo anterior ${ }^{4}$, presentando las interpretaciones que cabe hacer según los términos actuales del debate y ofreciendo mi punto de vista. La postura adoptada entonces respecto de estos problemas tuvo también consecuencias respecto del tercero, aunque en ese momento no me aventuré a proponer un candidato para identificar al físico citado, sino que sólo ofrecí unas características que sirvieran de base para su identificación.

Pues bien, en este trabajo pretendo completar la tarea emprendida intentando establecer qué filósofo puede ser el físico aludido en el papiro, tomando como criterio de búsqueda las características esbozadas.

\section{EL TEXTO}

El texto de la columna IV resultante de la reconstrucción de Ferrari, que afecta a las seis primeras líneas, tiene una inusual y forzada sintaxis, y presenta adiciones importantes, lo que hace que debamos tomarlo con las debidas reservas y asumir su carácter conjetural. No obstante, la propuesta de Ferrari,

${ }^{2}$ Ferrari 2010, pp. 137-148.

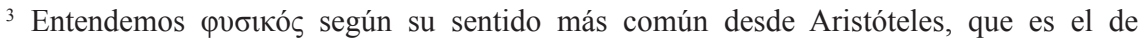
filósofo de la naturaleza. Esta es la acepción que se compadece mejor con el tipo de intelectual a que se alude en el papiro. No es verosímil que tenga el sentido de «médico», como cree Ferrari 2010, p. 143, y menos por las razones que aduce: que el término no está atestiguado antes de Aristóteles en el sentido de «investigador de la naturaleza» o «filósofo natural» (el autor del papiro pudo ser contemporáneo de Aristóteles) o las relaciones de Demócrito con la medicina de su tiempo. De hecho, en la tradición doxográfica que nombra a Demócrito como pvбıкó $\varsigma$ y que el mismo Ferrari trae a colación, el término tiene siempre el sentido de «filósofo natural» y no el de «médico».

${ }^{4}$ Megino 2012, pp. 781-790. 
consistente principalmente en la adición del fragmento papiráceo $\mathrm{F} 14$ junto al G 4, y en la del F 17 junto con $\mathrm{H} 46$ y F $15^{5}$, se basa en sólidos criterios papirológicos, y hasta donde yo sé, todavía no ha sido rechazada por otros especialistas ${ }^{6}$. Tomo, pues, dicho texto como base de mi análisis, aunque optando por otras lecturas para colmar algunas lagunas en las líneas 4 y 5 , ya que las preferidas por Ferrari eran menos probables ${ }^{7}$. Sigo el texto de Ferrari hasta la línea 6. El resto es el de la edición de Bernabé 2007, pp. 190 ss., con algunas variantes que señalo en el aparato crítico:

] $\dot{v} \pi \dot{\alpha} \dot{\alpha} \mu \mu[\alpha v \varepsilon$

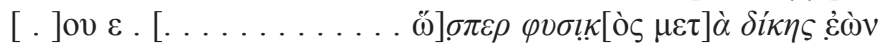

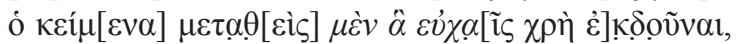

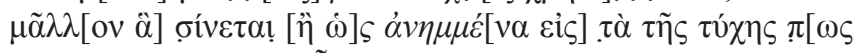

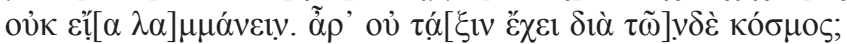

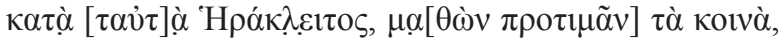

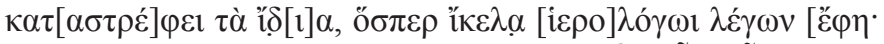

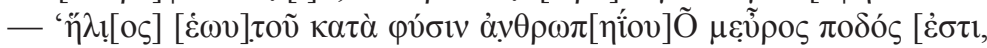

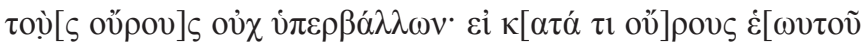

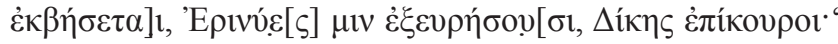
$\dot{v} \pi \varepsilon \rho] \beta \alpha \tau \grave{\jmath} \mu \pi \mathrm{o \eta ̄ \imath} \kappa[$

$$
\begin{aligned}
& \text { ]ọı } \theta u ́ 0 y[\sigma r
\end{aligned}
$$

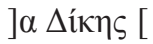

$$
\begin{aligned}
& \text { ] } \mu \eta v \grave{~} \tau \alpha \kappa[\tau \tilde{\omega} \iota
\end{aligned}
$$

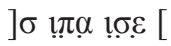

${ }^{5}$ Resalto en cursiva la parte del texto añadida por estos fragmentos. Sobre la nomenclatura de éstos y todo lo relativo al hallazgo y reconstrucción del Papiro de Derveni, cf. Kouremenos, Parássoglou, y Tsantsanoglou 2006, pp. 1 ss. (en adelante KPT).

${ }^{6}$ Burkert 2011, pp. 161 164, ofrece una reconstrucción alternativa de la columna, pero sin tener en cuenta las adiciones de Ferrari. Se trata de una reconstrucción conjetural, que arroja un sentido completamente distinto. Debido a que mi interés se centra en discutir el texto de Ferrari, dejaré de lado el de Burkert, sin prejuzgar con ello la superioridad de uno sobre el otro. Ferrari 2011b, pp. 365-370, se ha vuelto a ocupar de la col. IV, pero focalizando su atención en las líneas 10-13, que no son objeto de análisis aquí.

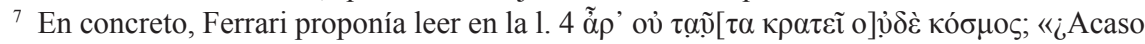
no es cierto que ni siquiera el orden del mundo domina estas cosas (i. e. las vicisitudes del

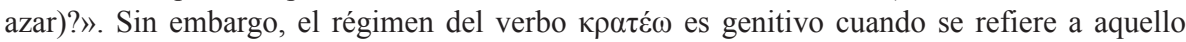

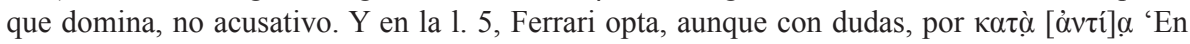
cambio' o 'por el contrario', locución sólo atestiguada en poesía tardía (Opp., Hal. II 555 y

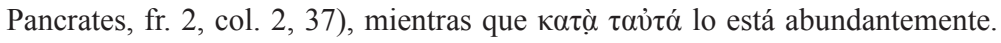


0 supplevit Ferrari (2010) 1 Ø̋] $\sigma \pi \varepsilon \rho$ Janko: oĩ] $\alpha \pi \varepsilon \rho$ vel $\kappa \alpha \theta] \underline{\alpha} \pi \varepsilon \rho$ KPT ॥

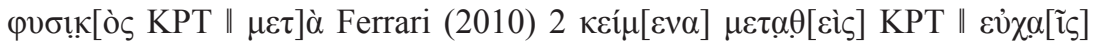

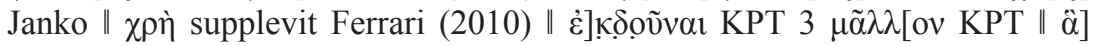

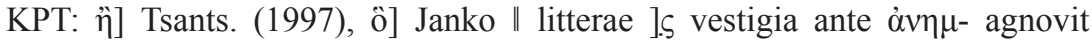

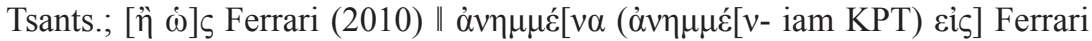
(2010) $\| \pi[\omega \varsigma$ Bernabé (en prensa): $\pi[\tilde{\omega} \varsigma$ Ferrari (2010), yò $[\rho \mathrm{KPT}, \pi[\alpha \dot{\theta} \eta \eta$

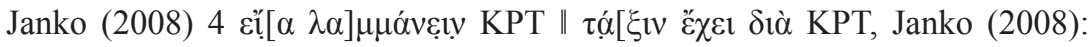

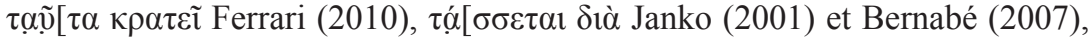

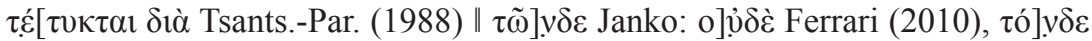

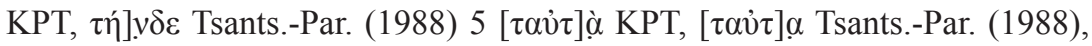

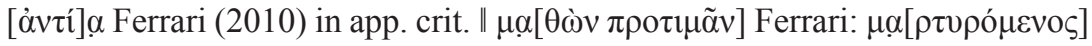

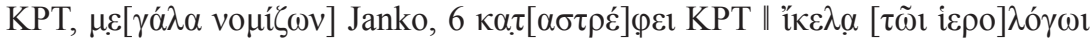

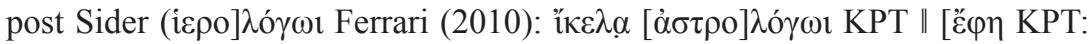

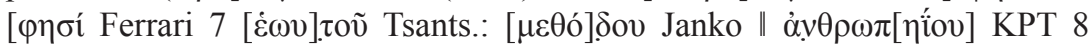

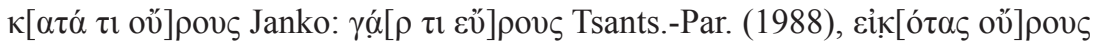

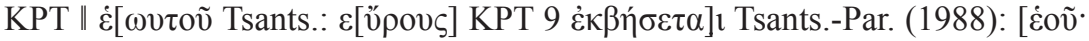

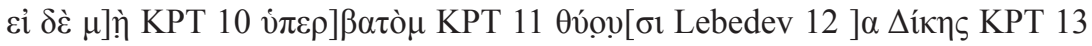
$\mu \eta v i ̀ ~ \tau \alpha \kappa[\tau \tilde{\omega} \iota \mathrm{KPT}: \dot{\alpha}] \mu \eta ́ v ı \tau \alpha \kappa[$ Janko

... (él) suponía ... como si fuera en justicia un físico, el que ha alterado cosas establecidas que hay que confiar a las plegarias, no permitía considerar las cosas que dañan más que como ligadas de algún modo a las vicisitudes del azar $^{8}$. ¿Acaso el mundo no tiene un orden por medio de esas cosas (i. e. sirviéndose de las vicisitudes del azar)? Conforme a esto mismo ${ }^{9}$, Heráclito, habiendo aprendido a estimar más las cosas comunes, refuta las particulares ${ }^{10}$, el cual precisamente dice, hablando igual que el autor de relatos sagrados ( $s c$. Orfeo) (cf. Heraclit., Fr. 57 y 52 Marc. = 22 B 3 y 94 D.-K.):

${ }^{8}$ Sería posible también considerar $\pi \tilde{\omega} \varsigma$ como adverbio interrogativo y traducir: «¿Cómo no permite considerar las cosas que dañan más que como ligadas a las vicisitudes del azar?». Ferrari 2010, p. 145 justifica esta extraña sintaxis, frente a la que sería más normativa: $\pi \tilde{\omega} \varsigma$

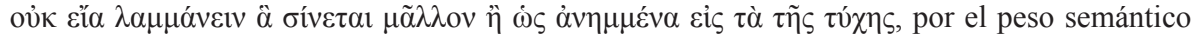

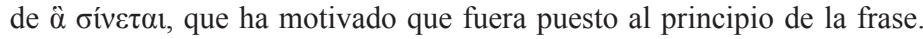

9 Es decir, a la idea de que el orden del mundo domina todas las cosas, incluido el azar.

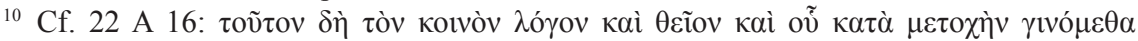

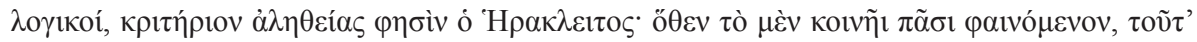

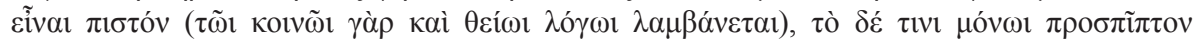

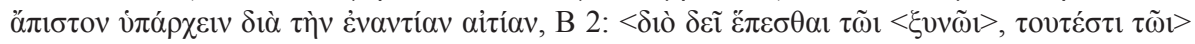

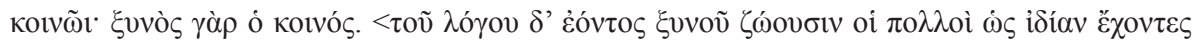

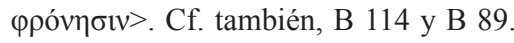


«El sol, según su propia naturaleza, tiene la anchura de un pie humano, sin rebasar sus límites, pues si excede en algo sus propios límites, las Erinis, defensoras de la Justicia, lo descubrirán», ... haga que $<$ el sol $>$ se exceda ... sacrifican ... de Justicia ... en un mes determinado ...

\section{PUnTO DE PARTIDA}

En el análisis que hice de la columna en mi anterior trabajo, sostuve lo siguiente:

$1^{\circ}$. La alusión al físico tiene como fin criticar una postura anti-tradicional sobre la plegaria ( $\varepsilon \chi_{\chi}$ ) fundada en un supuesto teológico que hace al azar

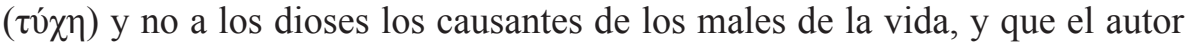
del papiro considera contraria al modo correcto de invocar a los dioses.

$2^{\circ}$. La atribución al azar de dichos males y su consideración como agente independiente del orden divino del mundo forma parte de la opinión criticada por el autor del papiro ${ }^{11}$.

$3^{\circ}$. El autor expone la opinión del físico para refutarla.

Las razones que aducía para defender estas tesis se basaban en la comparación entre la opinión atribuida al físico y la postura del autor del papiro respecto de dos conceptos: la plegaria a los dioses y el azar, demostrando que ambas opiniones eran diferentes.

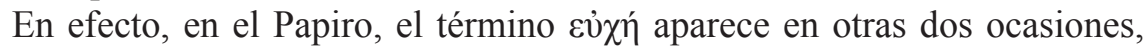
una en la col. I, según la reconstrucción de Ferrari ${ }^{12}$, y otra en la primera línea de la col. VI. Es decir, todas en las primeras columnas del papiro, en las que el autor describe y comenta un ritual de tipo mistérico en el que tienen un papel destacado las Erinis, diosas del inframundo cuya función es vengar y

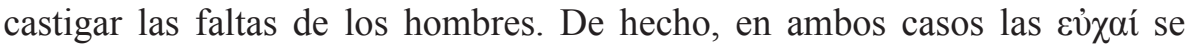
dirigen, por lo que podemos deducir de la col. III, confirmado por la col. VI, a las Erinis. Se trata de plegarias propiciatorias que tienen como objeto prin-

${ }^{11}$ Que el físico sostuviera que el orden del mundo no podía evitar los efectos perniciosos del azar y que, por tanto, éstos se sustraerían a su poder ordenador, puede deducirse de la pregunta: «¿Acaso el mundo no tiene un orden por medio de esas cosas?», con la que el autor del papiro parece querer afirmar lo que el físico negaba.

${ }^{12}$ Ferrari 2011a, p. 42. 
cipal evitar el castigo de estas diosas en este o en el otro mundo, y, por tanto, alejar el mal que estas divinidades puedan ocasionar de los que se inician en el rito. Así pues, estas plegarias tienen como fundamento la creencia en que las divinidades a las que se dirigen tienen poder para satisfacerlas, del mismo modo que lo han tenido para causar los males que las han motivado.

Esta concepción de la plegaria a los dioses es perfectamente congruente con la noción tradicional, en la que aquélla se concibe como una petición a la divinidad para que con su poder beneficie de algún modo al peticionario ${ }^{13}$. Las plegarias suponen siempre que sus destinatarios pueden responder con eficacia a ellas.

Por consiguiente, el autor del papiro comparte la concepción tradicional de las invocaciones a los dioses y no la modificación que el físico innominado ha realizado en el sentido de que no caben en ellas peticiones de salvaguarda de los males, porque éstos dependen del azar. El autor asume que los dioses son responsables de los males que acontecen a los hombres, de modo que para él éstos no dependen sólo del azar.

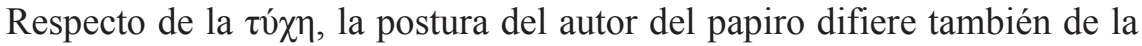
del físico, según el cual el orden cósmico sancionado sería impotente frente al azar como causante de los males humanos. La cuestión no es si para el autor del papiro el azar tiene algún papel dentro del orden de las cosas, sino si prevalece sobre el orden en todo aquello considerado como nocivo o pernicioso. Esto lo sabemos examinando tres cosas: primera, cuál es la doctrina del autor sobre el azar ( $\tau \dot{\chi} \chi \eta)$; segunda, qué es el causante de lo que daña al hombre en el papiro; y tercera, qué concepción hay en éste de la estructura y gobierno del cosmos.

En cuanto a la primera, existe el inconveniente de que el autor del papiro no menciona el azar en ninguna ocasión más, con lo que no tenemos un término de comparación. No obstante, sí podemos hacernos una idea de qué podría entender éste por azar acudiendo a la tradición anterior y a la literatura filosófica más o menos contemporánea del autor del papiro.

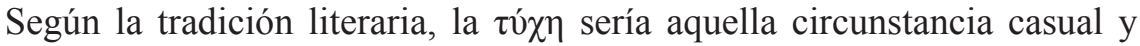
fortuita que no se prevé y está fuera del control humano, pero que, sin embargo, produce un efecto que puede ser bueno o malo ${ }^{14}$. Ese carácter incon-

${ }^{13}$ Cf. p. ej. Od. X 526, Hes., Th. 419, Thgn. 341, Hdt. I 31.24, Pi., O. IV 15, S., El. 636.

${ }^{14}$ Cf. p. ej. Thales, 11 A 1 DK, Aristox. 58 D 11 DK = fr. 41 Wehrli, Men. fr. 247, Com. IV p. 288, Cleobul. ap. Stob. IV 44.75., E., Fr. 554 N. ${ }^{2}$ ap. Stob. IV 41.44. Cf. también Democr. 68 B 176. 
trolable del azar provoca que algunos autores consideren que tiene un carácter divino ${ }^{15}$ y que gobierna todas las $\operatorname{cosas}^{16}$, e incluso que los dioses también están sujetos a su poder ${ }^{17}$. De ahí que también sea objeto de plegarias ${ }^{18}$. Entre los filósofos, el que ofrece una definición más acabada del azar es Aristóteles, para quien el azar es una causa accidental indeterminada de aquello que no sucede necesariamente, ni la mayoría de las veces, ni de un modo regular, y que concurre en las cosas que se hacen con un fin y que son objeto de elección. Una causa a la que se alude cuando no se conoce la causa determinada que produce el mismo efecto ${ }^{19}$.

A la luz de estos testimonios, podemos suponer que para el autor del papiro el azar podría ser una causa eficiente imprevisible e incontrolable para el hombre, que actúa independientemente del orden natural regular que domina todas las cosas.

En cuanto a la segunda cuestión: qué es lo que daña al hombre en el papiro, parece claro, a la luz de las primeras columnas, que lo que perjudica al hombre es la acción de las divinidades que pueden castigar sus faltas y a las que hay que apaciguar, que son las Erinis y «los démones que estorban» de la col. VI. Divinidades que, por otra parte, son las garantes del orden establecido, como defensoras de la Justicia.

A la tercera cuestión, cuál es la concepción de la estructura y gobierno del cosmos en el papiro, puede responderse a la luz de las cols. XIII y ss.: el cosmos es un conjunto ordenado de elementos unidos entre sí según un orden establecido por Zeus, dios que, como aire/intelecto, es todo en todas las cosas

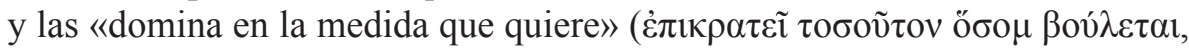
col. XIX).

Teniendo todo esto en cuenta, se puede ver fácilmente que, para el autor del papiro, el azar, entendido como causa fortuita e imprevisible, no prevalece sobre el orden en todo aquello considerado como nocivo o pernicioso, sino que de esto último sólo son causa las divinidades vengadoras y castigadoras que tienen como función restaurar el orden perturbado por las faltas humanas,

${ }^{15}$ Cf. p. ej. Hdt. I 126, III 139, etc., S., Ph. 1326, Pl., R. 592a. Esta opinión también la compartían los estoicos, cf. p. ej. SVF II 965.

${ }_{16}$ Men., Hypobol. fr. $3^{\text {b }}$, Com. IV p. 213. Cf. también Democr. 68 B 118.

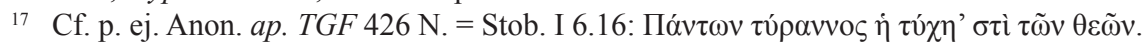

${ }^{18}$ Así p. ej. Cleóbulo, uno de los Siete Sabios, aconseja en una de sus máximas invocar

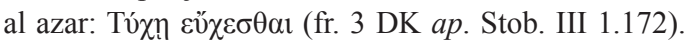

${ }^{19}$ Arist., Ph. II 5-6, $196 \mathrm{~b} 10$ ss., Rh. I 10, 1369a 32-b 1. 
y que actúan al servicio del orden cósmico establecido por Zeus, que es el que verdaderamente domina todas las cosas. Los males a los que el hombre se enfrenta y que tiene que combatir son expresión de ese mismo orden, que ha sido violado por la acción de los propios hombres. El azar, si tiene algún papel en la vida humana, nunca lo podrá tener a costa del orden del mundo.

De todo esto, deducía otras dos conclusiones:

$4^{\circ}$. La cita de Heráclito tendría como fin apoyar la refutación de la opinión del físico. Esto es así, porque el autor del papiro comparte la idea de Heráclito de que las Erinis, como servidoras de la Justicia, son las guardianas del orden regular del mundo, según el cual hay unos límites que todas las cosas tienen que respetar.

$5^{\circ}$. Heráclito no puede ser el físico en cuestión ${ }^{20}$, sino que éste habría que buscarlo en algún filósofo de la naturaleza que defendiera una postura anti-tradicional sobre la pertinencia de las plegarias a los dioses basada en la asunción de que dichas plegarias son ineficaces para protegerse del mal, por provenir éste del azar, ante el cual el orden de las cosas, garantizado por los dioses, se muestra impotente.

Estos son, pues, los presupuestos de los que parto. De lo que se trata ahora es de ver quién puede responder mejor a las características que acabamos de enunciar.

Ferrari ha afirmado que el físico es Demócrito ${ }^{21}$. Aduce que este pensador representa bien la figura del intelectual que ha alterado los elementos fundamentales del culto y de la fe tradicionales que deben pertenecer al ámbito de la plegaria, y que considera los aspectos nocivos de la experiencia como accidentes del azar.

Para fundar su tesis, recurre a la doctrina democrítea de los $\varepsilon \Uparrow \delta \omega \lambda \alpha$, imágenes formadas por agregados de átomos que representan a todos los seres que las emiten (sean objetos, animales o personas), y que atravesando el aire entran en los cuerpos de sus perceptores formando en su alma una represen-

${ }^{20}$ Tal como propone Bernabé (en prensa), para quien el autor del papiro concuerda con la opinión del físico respecto de las plegarias a los dioses y del papel del azar como causante de los males que motivan dichas plegarias. Y también, que acepta la impotencia del orden cósmico frente al azar como agente de los males del mundo, de modo que la cita de Heráclito sería una confirmación de este punto de vista, por lo que el físico aludido es el mismo Heráclito.

${ }^{21}$ Ferrari 2010, pp. 141 ss. 
tación del ser del que han salido. Estas imágenes tienen carácter divino y pueden afectar a los hombres para favorecerles o para perjudicarles ${ }^{22}$.

Demócrito, según Ferrari, consciente de esta función de las imágenes divinas, oraba para encontrarse con imágenes propicias ${ }^{23}$. Este ejercicio de la plegaria sería congruente con un proyecto ético y psicológico que buscaba alcanzar el bienestar, el buen ánimo y la ausencia de temor, y comportaba un replanteamiento de la religión, según el cual, aun admitiéndose la existencia de fenómenos divinos, se los reducía a mecanismos de un sistema determinista fundado en la diversa cualidad y movimiento de los átomos.

La plegaria de Demócrito, según Ferrari, sería la propia de una mente ilustrada, que pide a los dioses que favorezcan la serenidad del ánimo, pero que niega que los dioses sean responsables de los aspectos nocivos de la experiencia o de la religión, los cuales dependerían más bien del azar.

Para Ferrari, esta concepción de la plegaria, contraria a la creencia tradicional, sería rechazada por el autor del papiro, quien reprocharía a Demócrito la contradicción que supondría asumir los aspectos pacíficos y saludables de la plegaria y atribuir al mismo tiempo al azar los aspectos nocivos de la realidad ${ }^{24}$.

Hasta aquí la argumentación de Ferrari. Pienso que es correcta en líneas generales, presentando a un Demócrito que cumple de modo razonable las características que he propuesto como criterio de búsqueda, de modo que también en mi opinión lo más probable es que el físico en cuestión sea Demócrito. Sin embargo, creo que pueden ofrecerse más argumentos a favor de esta tesis. Así, por ejemplo, Ferrari no hace alusión a otros posibles candida-

${ }^{22} 68$ A $74=$ Cic., ND I 43.120.

${ }^{23} 68$ B 166 DK = S. E., M. IX 19: «Dice Demócrito que algunas imágenes se acercan a los hombres y que, de ellas, unas son benéficas y otras, perjudiciales; de ahí que él implorara

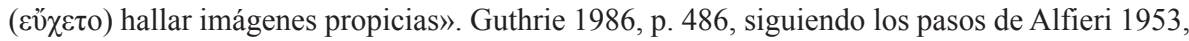

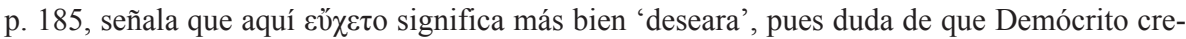
yera en la eficacia de la plegaria a estas imágenes, como sugiere, según él, el fr. 30 DK. Sin embargo, estoy de acuerdo con Ferrari 2010, p. 141 n. 3, cuando dice que no es probable que

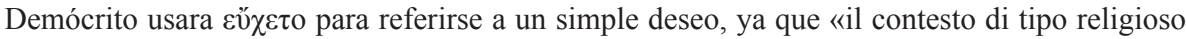
suggerisce un riferimento alla fenomenología della preghiera per quanto questa potesse essere stata modificata rispetto al costume tradizionale».

${ }^{24} \mathrm{La}$ identificación del físico con Demócrito implica atribuir a éste las ideas sobre la plegaria y el azar que el autor del papiro critica. No obstante, eso no es óbice, creemos, para aceptar que el autor del papiro se haya visto influido por Demócrito en otros aspectos, como ha puesto de manifiesto, p. ej., Burkert 2010. 
tos para demostrar que la probabilidad de que ellos sean el físico en cuestión es menor. No profundiza en la concepción religiosa de Demócrito para contraponerla con la del autor del papiro, p. ej., respecto del temor a los dioses o la noción del Más Allá, aunque se haga alusión a ella. Y tampoco analiza apenas la función que para Demócrito tenía el azar en relación con su papel en la experiencia humana del mal. No hace, en suma, una fundamentación de carácter filosófico que ponga en evidencia de un modo sistemático las concomitancias conceptuales e ideológicas que Demócrito tiene con el físico. No quiero desmerecer con ello el artículo de Ferrari, cuya perspicacia y buen hacer me parecen incuestionables, sino sólo fundamentar con nuevos argumentos su intuición de que Demócrito y el físico son la misma persona.

\section{Otros CANDidatos}

Lo primero es mostrar, aunque sea brevemente, que entre los фvбıкоí a los que pudiera aludir el autor del papiro, ninguno responde tan bien a las opiniones que le atribuye como Demócrito. Los criterios que hay que emplear para la búsqueda son, por un lado, la doctrina de éstos sobre la plegaria, y, por otro, su concepción del azar como responsable del mal en el mundo.

Entre aquellos a los que la tradición denomina pvбıкoí, uno es el propio Heráclito $^{25}$, quien critica las plegarias tradicionales a los dioses:

Y les rezan a esas estatuas, como si uno estuviera charlando con las paredes, sin saber en absoluto quiénes son realmente dioses y héroes ${ }^{26}$.

Y parece aludir al azar como parte integral del orden cósmico:

Como el más hermoso de los montones dispersos a voleo es el cosmos, dice Heráclito ${ }^{27}$.

Pero ya hemos dicho que hay que descartarlo.

${ }^{25}$ Véase p. ej., 22 A 1a, A 16.

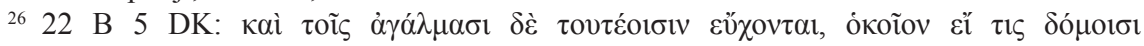

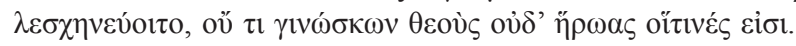

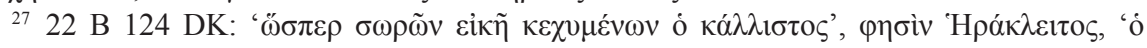

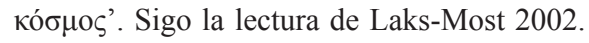


En primer lugar, la crítica de Heráclito no tiene por qué ser a la plegaria como tal, sino más bien a la ignorancia de quienes la hacen, que rezan sin saber en realidad quiénes son los dioses y héroes a los que dirigen sus rezos, pues los identifican erróneamente con sus estatuas ${ }^{28}$. Esta ignorancia tiene que ver, según parece, con la creencia en que los dioses habitan realmente en sus representaciones plásticas, que Heráclito negaría, no con el desconocimiento de que los dioses no tienen que ver con los aspectos de la vida que la plegaria pretende evitar. La oposición de Heráclito a la plegaria ordinaria no se funda, como la del físico, en la consideración de los dioses como irresponsables de los efectos perniciosos de la existencia, sino más bien en el sinsentido que tiene rezar a unas estatuas inertes, que no son dobles de la divinidad, sino meras representaciones suyas. De hecho, la concepción heraclítea de la divinidad es más bien algo que abarca tanto lo bueno como lo malo, es decir, un principio subyacente a las oposiciones de contrarios ${ }^{29}$. De ahí que, según Heráclito, la distinción entre bueno o malo, justo o injusto, sea propia del hombre, no de dios, para quien, «todas las cosas son bellas, buenas y justas $»^{30}$.

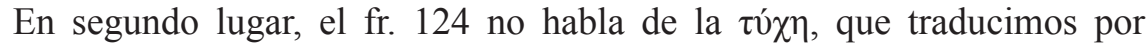

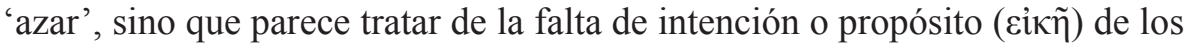
principios que configuran el cosmos, la cual se refiere a su falta de finalidad, no a que sea debido a una causa accidental e imprevisible, como es la $\tau \dot{\chi} \chi \eta^{31}$.

${ }^{28}$ Sobre este fragmento, véase p. ej. Marcovich 1968, p. 107 (para quien Heráclito ataca aquí el antropomorfismo y la idolatría de la religión tradicional); Mondolfo 1971², pp. 65, 345 s. (quien ve este fragmento como un reproche a los ritos que no son remedios espirituales [cf. fr. $68 \mathrm{DK}$ ], es decir, los ritos que implicaban un culto a las imágenes bajo el supuesto de la presencia divina en ellas); Bollack y Wismann 1972, p. 73 (que señalan también el absurdo del rito a estatuas mudas por la ausencia del dios); Guthrie 1986, p. 444 (quien opina que Heráclito condena la práctica de elevar plegarias a los ídolos [no la plegaria como tal]); Kahn 1979, p. 267 (quien ve una crítica a la idolatría y al culto antropomórfico); García Calvo 1985, pp. 343-6 (quien interpreta la crítica a la ignorancia de los hombres o, más bien, según él, a su creencia falsa, como crítica a las prácticas de culto religioso); Conche 1986, pp. 175 s. (quien cree que Heráclito se burla de la plegaria a estatuas sin vida divina en ellas); Robinson 1987, p. 78 (quien ve el fragmento como un ataque a la práctica religiosa antropomórfica común). Sobre las ideas religiosas de Heráclito, véase también Babut 1975, pp. 27-62 y Adomenas 1999, pp. 87-113.

2922 B 67 DK, B 53. Cf. Guthrie 1986, pp. 444s.

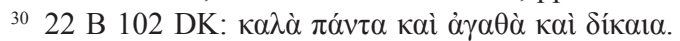

${ }^{31}$ Independientemente de que Heráclito esté expresando en este fragmento su propia opinión (manifestando una concordancia de contrarios en el orden cósmico como producto de un montón de elementos desordenados) o más bien la de la mayoría de los hombres, que 


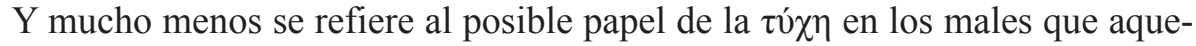

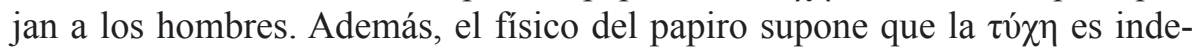
pendiente en su acción del orden del mundo, lo que se contradice claramente con la opinión de Heráclito, quien insiste en que todo lo gobierna el fuego cósmico $^{32}$, trasunto del $\lambda$ ó os común ${ }^{33}$.

De hecho, la posterior alusión a Heráclito en el papiro tiene como fin apoyar la refutación de la opinión del físico, no confirmarla, ya que se opone a la idea de que haya algo que escape al orden racional del mundo, vigilado por las Erinis.

Otro posible candidato sería Anaxágoras, de quien se dice que no sólo hizo del azar ( $\tau \dot{\chi} \chi \eta)$ una causa de las $\operatorname{cosas}^{34}$, sino que negó la providencia de los dioses hacia los hombres, afirmando que «todos los asuntos humanos son dirigidos por el azar» ${ }^{35}$. Precisamente, esta actitud racionalista hacia los dioses tradicionales, tendente a sustituir lo divino por causas naturales, le llevó a ser condenado por impiedad ${ }^{36}$.

Sin embargo, no conocemos de Anaxágoras ninguna postura respecto de la plegaria. Y tampoco tenemos constancia de que atribuyera al azar los males humanos. Además, comparte con el autor del papiro una concepción si-

no comprenden el $\lambda$ ó $\gamma$ os. Sobre este debatido fragmento, cf. p. ej. Gutas (ed.) 2010, p. 328; Most 1988, pp. 224-256, así como las obras citadas en n. 28.

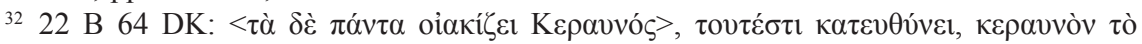

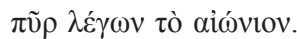

3322 A 8 , B 1, B 31 DK.

3459 A 66 = Aët. I 29.7: «Anaxágoras, Demócrito y los estoicos piensan que el azar es una causa oculta al razonamiento humano, pues unas cosas son debidas a la necesidad, otras, al destino, otras, a la libre elección, otras, al azar y otras, a la casualidad». Para Anaxágoras, el intelecto (voṽ $)$ sería una mera causa primera eficiente, que no implica ninguna ordenación teleológica del cosmos (59 A 47), sino un orden mecanicista sujeto a causas segundas. Así, cada cosa tendría una causa natural, entre las cuales se podía contar el azar, aun cuando el azar no fuera la causa primera del orden del mundo (cf. 59 A 15).

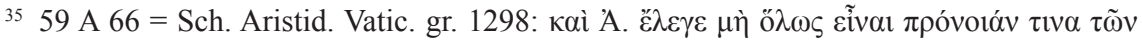

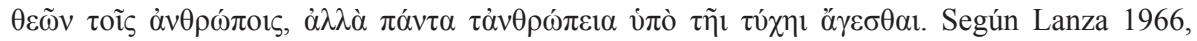

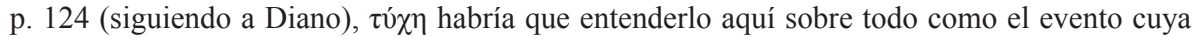
causa no es conocida, aunque se cuente entre las causas naturales, y que por eso supone una

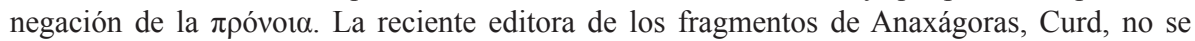
ocupa del testimonio: cf. Curd 2007.

3659 A 1, A 3, A 17. Es significativo lo que dice a este respecto Plutarco, Nic. 23 (59 A 18), quien atribuye la prisión de Anaxágoras al rechazo que en Atenas sufrían los físicos, debido a que «reducían lo divino a causas irracionales, potencias no sujetas a la providencia y sucesos necesarios». 
milar del voṽ en tanto que fuerza dominadora del orden cósmico $^{37}$, mientras que el físico del papiro es criticado precisamente por el papel preponderante que atribuye al azar frente a dicho orden. Por tanto, no tenemos elementos suficientes para pensar que Anaxágoras sea el físico en cuestión.

Menos posibilidades tienen otros autores, como Empédocles o Pródico. El primero sólo alude una vez a la plegaria, cuando en el fr. 131 D.-K. invoca suplicante a la musa Calíope para que le asista en la exposición de su discurso sobre los dioses ${ }^{38}$. Una invocación que encaja perfectamente con la tradicional petición a las Musas para que inspiren el canto del poeta, como podemos ver, para el caso de Calíope, en Alcmán ${ }^{39}$. En cuanto al azar, sólo hace dos referencias a él: una, en el fr. 103 D.-K., donde dice que cada cosa tiene pensamiento por deseo del azar, aludiendo al azar de la proporción de los elementos que constituyen cada cosa, de la que depende la índole de su actividad psíquica ${ }^{40}$; y otra, en el fr. 85 D.-K., donde en un contexto en el que se hablaría de la formación de las distintas partes de los seres vivos mediante la combinación azarosa de los elementos raíces bajo la acción de Afrodita, dice, en referencia a la composición del ojo, que a la llama le tocó en suerte ( $\tau u ́ \chi \varepsilon)$ la tierra ${ }^{41}$. En ambos casos, las alusiones al azar no tienen nada que ver con su responsabilidad en la experiencia humana del mal, que, para Empédocles, habría que atribuir más bien a la Discordia ${ }^{42}$.

En cuanto a Pródico, su similitud al físico citado en el papiro sería su denominación de $\varphi v \sigma i \kappa o ́ s{ }^{43}$, algo, por lo demás, muy común en otros autores presocráticos, y su concepción racionalista de los dioses, cuyo origen atribuía a la tendencia humana a considerar dios a lo que es útil o provechoso para la vida, como el sol, la luna, los ríos etc. ${ }^{44}$ Todo ello, desde luego, muy insuficiente para identificar a Pródico con nuestro físico.

3759 B 12 = Simp., in Ph. 156.13 ss. Cf. Bernabé 2004, pp. 176 ss.

3831 B 131 D.-K.: « Pues si a causa de alguno de los seres efímeros, inmortal Musa / < te plugo $>$ que nuestras atenciones tu interés movieran, / asiste ahora de nuevo a este suplicante

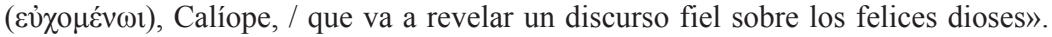

${ }^{39}$ Fr. 27 Page: «Vamos, Musa, Calíope, hija de Zeus, / comienza estos versos amados, presta deseo al canto / y gracia al coro».

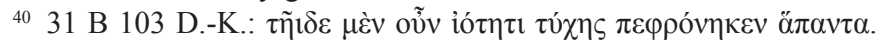

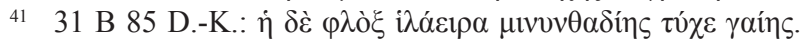

${ }^{42}$ Cf. p. ej. 31 B 115 D.-K.

4384 A 1 D.-K.

4484 B 5 D.-K. 
Ningún candidato, por tanto, tiene tantas probabilidades como Demócrito para ser el físico aludido.

Ahora sólo queda mostrar en qué nos fundamos para defender esta afirmación.

\section{Argumentos a faVor de Demócrito}

En primer lugar, Demócrito tiene una concepción de la función de la plegaria muy similar a la del físico. Demócrito, cuando trata de la plegaria, elude también usarla como mecanismo de apaciguamiento o de petición de favores a los dioses ${ }^{45}$. Así, por ejemplo, en el fr. 166 D.-K., cuando habla de las imágenes que se acercan a los hombres, que son divinas ${ }^{46}$, no dice que

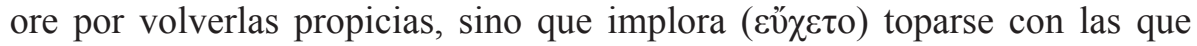
son benéficas, es decir, expresa un deseo para que le favorezca la suerte de hallar imágenes propicias, no una plegaria a éstas que implique considerarlas responsables de un mal que Demócrito pretende evitar ${ }^{47}$.

Además, Demócrito se expresa claramente contra la utilidad del tipo de plegaria que pide salud a los dioses, utilizando una razón análoga a la que emplea el físico: su ineficacia, debido a que atribuye a los dioses un poder para satisfacerla que no les corresponde. Lo vemos en el fr. 234 D.-K., donde se dice:

Los hombres piden salud a los dioses con sus plegarias, pero no saben que el poder sobre ella lo tienen en sí mismos. Al hacer por intemperancia lo contrario a ella, se vuelven traidores a su salud a causa de sus apetitos ${ }^{48}$.

\footnotetext{
${ }^{45}$ Sobre las concepciones religiosas de Demócrito, véase p. ej., Jaeger 1952, pp. 180 ss., McGibbon 1965, pp. 385-397, Eisenberger 1970, pp. 141-158, Henrichs 1975, pp. 93-123, Guthrie 1986, pp. 485-489.

${ }^{46}$ Así lo parece, aunque no está del todo claro si Demócrito creyó verdaderamente en la divinidad de estas imágenes. De todos modos, algunos autores sí le atribuyen esa creencia, cf. p. ej. Cic., $N$ D. I 12.29, 43.120. Sobre la cuestión, véase p. ej. Guthrie 1986, pp. 487 s.

${ }^{47}$ Esto no quiere decir, como pretende Alfieri 1953, p. 185, basándose en este fragmento y en el fr. 234 D.-K., que Demócrito no tuviera un concepto de «plegaria». Poseía una noción ilustrada, alejada de la tradicional, pero existente, al fin y al cabo.

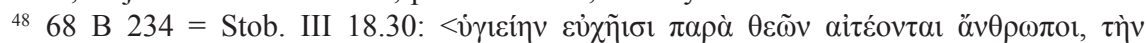

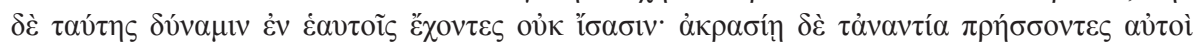

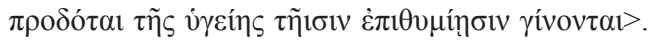


Asimismo, esta razón de la inutilidad de la plegaria responde en Demócrito a la misma idea que encontramos en el físico: la de que no hay que atribuir a los dioses lo nocivo. Así lo dice Demócrito en el fr. 175 D.-K.:

Los dioses dan a los hombres todos los bienes, antaño y ahora, excepto cuanto es malo, perjudicial e inútil; estas cosas los dioses no las otorgan a los hombres ni antaño ni ahora, sino que éstos se acercan a ellas por ceguera de mente e insensate $z^{49}$.

De hecho, la coincidencia entre Demócrito y el físico parece obedecer a una actitud religiosa común, caracterizada por una tendencia a racionalizar el papel tradicional de los dioses mediante la atribución de sus acciones a causas naturales. El físico no permitía considerar las cosas que dañan a los hombres más que como debidas al azar, haciendo por ello a las plegarias superfluas. Demócrito prefiere una explicación psicológico-moral, la intemperancia y la insensatez humana, pero su voluntad de negar a los dioses su función de causa de los males humanos es la misma.

La postura racionalista de Demócrito llega hasta el punto de ironizar sobre los hombres «doctos» ( $\lambda$ ó 1 iol) que tendían sus manos al aire llamándolo Zeus y atribuyéndole, en tono hímnico, la completa sabiduría, potencia y soberanía sobre todas las cosas, tal como vemos en el fr. $30^{50}$. Para Demócrito, la creencia en los dioses tuvo su origen en el temor de los hombres hacia los fenómenos celestes, cuyo poder les hizo divinizarlos ${ }^{51}$. A juzgar por el fr. 30, es

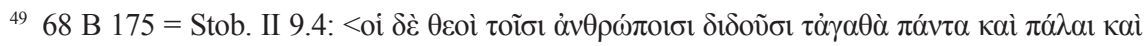

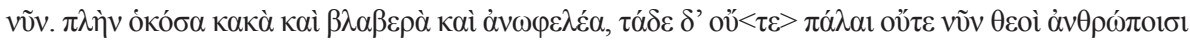

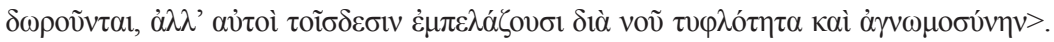

${ }^{50} 68$ B 30 = Clem. Al., Prot. 68, Strom. V 103: «Pocos fueron, entre los hombres doctos, aquellos que, alzando sus manos hacia el lugar al que los griegos llamamos ahora 'aire', dijeron: "Zeus lo dice todo (para que ocurra) y todo lo sabe, todo puede darlo y quitarlo, y él es rey de todas las cosas"». Cf. p. ej. Bailey 1928, p. 175. Otros autores, en cambio, no ven ninguna intención irónica en la referencia a estos hombres doctos, considerándolos como representantes genuinos de aquellos sabios antiguos que supieron dar cuenta del origen de los dioses: cf. p. ej. Jaeger 1952, pp. 183 s. Otros ejemplos pueden verse en Luria 2007, pp. 1250 s., aunque el mismo Luria es de la opinión contraria.

${ }^{51} 68$ A 75 = S. E., $M$. IX 24: «Hay quienes suponen que hemos llegado a tener noción de los dioses a partir de los sucesos maravillosos que se producen en el cosmos, opinión que parece ser también la de Demócrito. Dice: "En efecto, cuando los hombres antiguos vieron los fenómenos meteorológicos como truenos, relámpagos, rayos, conjunciones de los astros y eclipses del Sol y de la Luna, se atemorizaron ( $\dot{\varepsilon} \delta \varepsilon \mu \alpha \tau o \tilde{v} \tau \tau)$, creyendo que los dioses eran sus causantes"». 
muy probable que creyera que de esa misma actitud de temor proviniera también la plegaria. No se nos dice que el físico compartiera la teoría democrítea sobre el origen de la creencia en los dioses, ni que ironizara sobre la costumbre de algunos de llamar al aire «Zeus», pero su misma postura hacia la plegaria, que trasluce una postura racionalista hacia los dioses, y el rechazo hacia su doctrina del autor del papiro, que es uno de los que identifica al aire con Zeus, bien podría explicarse con ese trasfondo.

De hecho, es muy probable que el rechazo del físico de la plegaria tradicional, fundado en el supuesto de la irresponsabilidad de los dioses como agentes del sufrimiento humano, estuviera motivado por el deseo de desterrar el temor a éstos. Y en ese sentido, Demócrito es una buena guía también para comprender esa motivación. Demócrito declara que entre los males que aquejan al hombre y que perturban el buen ánimo ( $\varepsilon \dot{\theta} \theta v \mu i ́ \alpha)$, el estado de serenidad de alma que constituye el fin moral supremo, están las pasiones, y entre ellas, el temor a los dioses $(\delta \varepsilon 1 \sigma 1 \delta \alpha 1 \mu o v i ́ \alpha)^{52}$. Un temor que no hay que entender en este contexto como una mera actitud religiosa de veneración y respeto, sino más bien como un amedrentamiento ante lo divino, rayano con la superstición ${ }^{53}$. Una afección que para Demócrito resulta rechazable, ya que de los dioses no cabe tener miedo alguno en vida y mucho menos tras la muerte, pues con ella se produce una disolución total tanto del cuerpo como del alma. Por eso, tener miedo al Más Allá pensando que allí las malas acciones van a ser castigadas, es propio de quienes inventan mitos falsos ${ }^{54}$. No es descabellado pensar que estas ideas, que chocan frontalmente con las creencias religiosas del autor del papiro, estuvieran en la base de la doctrina del físico sobre la plegaria y la irresponsabilidad de los dioses en el sufrimiento humano.

Lo que quiero decir es que el físico y Demócrito no sólo comparten una misma actitud religiosa, sino que es precisamente esa actitud la que provoca

${ }^{52} 68$ A 1 = D. L. IX 45: «El fin <supremo> es el buen ánimo ( $\left.v \dot{\theta} \theta u \mu i ́ \alpha\right)$, que no es lo mismo que el placer, como han entendido algunos equivocadamente, sino aquello por lo cual el alma se mantiene serena y firme, sin ser turbada por ningún temor, miedo a los dioses

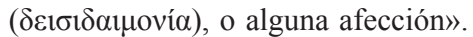

${ }^{53}$ Una interesante exposición de este tipo de afección la ofrece Teofrasto, Char. 6.

${ }^{54} 68$ B 297 = Stob. IV 52.40: «Algunos hombres, que desconocen la disolución de la naturaleza mortal, pero que son conscientes de que han actuado mal en su vida, sufren toda su existencia con confusiones y temores, porque han inventado fábulas ( $\mu \nu \theta 0 \pi \lambda \alpha \sigma \tau \varepsilon \dot{o v} \tau \varepsilon \varsigma$ ) acerca del tiempo posterior a la muerte». 
el rechazo del autor del papiro, cuya concepción religiosa es opuesta a la de ambos en los aspectos antedichos.

Nos queda analizar la función que para Demócrito tiene el azar en relación con su papel en la experiencia humana del mal y compararla con la del físico.

Como se sabe, la visión democrítea del mundo es determinista, mecanicista y carente de propósito o causa final. Todo sucede conforme a una necesidad fundada en la interacción de los átomos ${ }^{55}$. Eso quiere decir que todo ocurre por una razón ${ }^{56}$, y en virtud de esa razón, lo que ocurre, ocurre necesariamente. Y esa razón es la interacción de los átomos. ¿Qué papel tiene en este cuadro el azar ( $\tau \dot{\chi} \chi)$ ?

Demócrito parece que creía que el azar es una causa oculta a la mente humana $^{57}$. Esto está en consonancia con la concepción tradicional del azar, según la cual sería una circunstancia casual y fortuita que no se prevé y que está fuera del control humano, pero que surte efectos que pueden ser beneficiosos o perniciosos.

Por otra parte, como para Demócrito la necesidad que gobierna el orden cósmico y que otorga una explicación racional a lo que sucede, se funda en la interacción de los átomos, el azar debe ser compatible con dicha necesi$\mathrm{dad}^{58}$. Por lo tanto, el azar en el mundo es necesario, y su necesidad vendrá

5568 A 39 = Ps.-Plu., Strom. 7: «Absolutamente todo está predeterminado por la necesi-

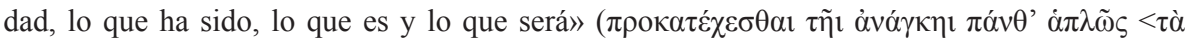

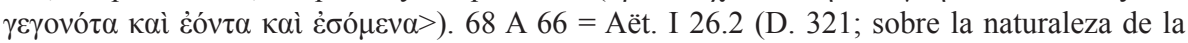
necesidad): «Demócrito dice que es la impenetrabilidad, el desplazamiento y el choque de la materia (i. e. de los átomos)».

5668 A 38 = Simp., in Ph. 28.15: «<Leucipo y Demócrito > afirman que sólo para quienes

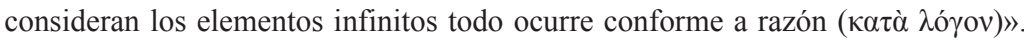

5768 A 70 = Arist., Ph. II 4, 196b 5-7: «Hay algunos a quienes les parece que el azar

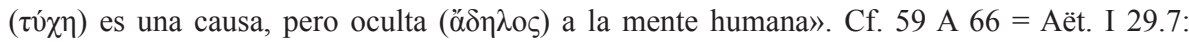
«Anaxágoras, Demócrito y los estoicos piensan que el azar es una causa oculta al razonamiento humano».

58 Lo cual está de acuerdo con el papel tradicional del azar, como testimonia la locución

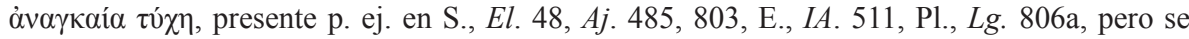
aleja de la concepción aristotélica de éste, para la que el azar «no puede ser causa ni de las cosas que suceden por necesidad y siempre ni de las que suceden la mayoría de las veces» (Arist., Ph. II 5, 196b 10-13). De ahí que Aristóteles atribuya a Demócrito la creencia en que nada sucede por azar, porque para éste hay una causa determinada de todo $(68$ A $68=$ Arist., $P h$. II 4, 195b 36). Lo único que habría causado el azar, entendido como la casualidad de la

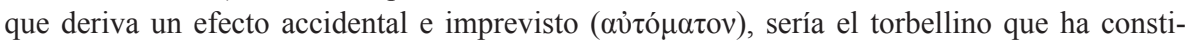
tuido el universo presente, y eso porque Aristóteles no reconoce en el torbellino democríteo 
determinada por la interacción de los átomos. Así, Demócrito verá el azar en el modo fortuito en que los átomos chocan unos con otros, originando con ello todos los seres compuestos, en virtud de la simetría de los propios átomos, que encajan entre sí conforme a su forma, posición, magnitud y orden ${ }^{59}$. El azar no es causa de este movimiento de los átomos, sino más bien del tipo de combinación determinada que origina los seres compuestos. Además, la interacción azarosa de los átomos no sólo es causa de los distintos seres individuales, sino también de las alteraciones cualitativas que originan sus cualidades sensibles ${ }^{60}$, así como sus afecciones y sensaciones ${ }^{61}$.

Así pues, para Demócrito lo azaroso tendría las características de lo indeterminado, necesario, universal y carente de finalidad, y se aplicaría a la combinación de los átomos que da lugar a la generación de los seres y las cualidades que los constituyen.

Ahora bien, ese carácter desconocido, oculto e imprevisible del azar hace pensar que para Demócrito el azar sea una mera noción subjetiva y no una verdadera causa en un mundo en el que todo sucede conforme a una razón. El azar vendría a ser un expediente que se usa cuando no se sabe la causa determinada de $\operatorname{algo}^{62}$.

Esto es especialmente aplicable en lo que concierne a la vida humana. Para Demócrito, el azar no es más que una imagen ( $\varepsilon^{\prime} \delta \omega \lambda$ ov) que el hombre se forma de la causa de lo que le sucede, motivada por su desconocimiento de la causa verdadera, mientras que lo que debe dirigir la vida de los hombres

una causa propia y determinada, no accidental del mundo. En similares términos se expresa Simplicio, in Ph. 330.14 (68 A 68).

5967 A 14 = Simp., in Cael. 242.15: «Estos átomos, que en el vacío infinito están separados unos de otros y se diferencian por sus formas, magnitudes, posición y orden, se desplazan en el vacío y, cuando se encuentran, chocan unos contra otros: unos rebotan al azar (ő $\pi \eta \uparrow$ òv $\tau u ́ \chi \omega \sigma ı v)$, otros se enlazan entre sí conforme a la simetría de sus formas, magnitudes, posiciones y órdenes, y permanecen así unidos para dar lugar a la generación de los compuestos». Cf. también, Dion. Alex. ap. Eus., PE XIV 23.2.3.

${ }^{60} 67$ A $9=$ Arist., $G C$ I 1, 315b, A $14=$ Simp., in Ph. 36.1 .

${ }^{61} 68$ A 49 = Gal. de elem. sec. Hipp. I 2.

${ }^{62}$ Eso explicaría que Simplicio diga que Demócrito, aunque pareciera valerse del azar en su cosmogonía, «en los casos particulares dice que el azar no es causa de nada, recurriendo entonces a otras causas; por ejemplo, la causa del descubrimiento de un tesoro es una excavación o la plantación de un olivo, así como de la fractura del cráneo de un calvo es el águila que deja caer la tortuga para que su caparazón se rompa» (68 A $68=$ Simp., Ph. 330.14). Cf. 68 A $68=$ Arist., Ph. II 4, 195b 36. Cf. Guthrie 1986, pp. 425 ss. 


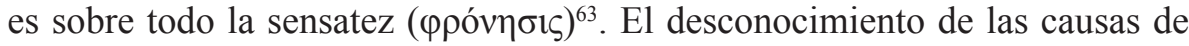
las cosas es signo de insensatez. Por eso, actuar movido por las ventajas que se esperan del azar y no por la sabiduría es propio de insensatos ${ }^{64}$. Esto es así también porque el azar es inconstante ${ }^{65}$, y por tanto no es ningún guía seguro de vida. Puede otorgar muchos bienes, pero también puede ser causa de desgracias, de las que nadie está libre ${ }^{66}$. El azar, por tanto, es causa de los males humanos en tanto que constituye una circunstancia aleatoria cuya índole es desconocida y sobre la que, en consecuencia, no se puede ejercer ningún control $^{67}$.

Ahora bien, ¿concuerda esta concepción del azar con la que el autor del papiro atribuye al físico? De éste se dice que no permitía considerar las cosas que dañan más que como ligadas de algún modo a las vicisitudes del azar. Con ello exoneraba a los dioses de responsabilidad y la trasladaba a una causa indefinida que no está sujeta al orden cósmico. Además, implicaba al azar en todos los casos de perjuicio que afectan al hombre.

Demócrito, como hemos visto, rechaza la responsabilidad de los dioses en el mal humano, y hace del azar causa de dicho mal, pero no en todos los casos. Y tampoco piensa que el azar sea independiente del orden cósmico. ¿Invalida esto la candidatura de Demócrito? Creo que no. Primero, porque

6368 B 119 = Dion. Alex. ap. Eus. PE XIV 27.5: «<Demócrito $>$ dice: "Los hombres

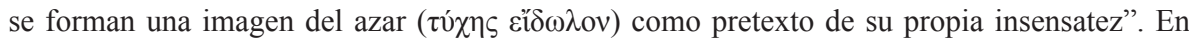
efecto, por su naturaleza, el azar se opone a la sensatez ( $\varphi \rho o ́ v \eta \sigma \iota \varsigma)$; y ellos dicen que el mayor enemigo de la sensatez la domina, o más bien, suprimiéndola y haciéndola desaparecer, ponen en su lugar al azar: en efecto, en lugar de exaltar a la sensatez como afortunada, exaltan al azar como muy sabio». Stob II 8.16: «De Demócrito: "Los hombres se forman una imagen del azar como pretexto de su propia irreflexión, pues el azar se opone poco a la sensatez, sino

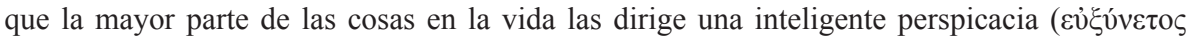
ỏ

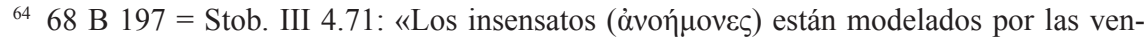
tajas del azar, pero quienes conocen estas cosas lo están por la sabiduría». Cf. también, 68 B $210=$ Stob. III 5.26: «El azar provee una mesa suntuosa; la prudencia ( $\sigma \omega \varphi \rho o \sigma v ́ v \eta)$, una suficiente».

${ }^{65} 68$ B $176=$ Stob. II 9.5: «El azar es generoso pero inconstante (àßś $\left.\beta \alpha 1 o \varsigma\right)$; la naturaleza, en cambio, es autosuficiente ( $\alpha$ $\tau \dot{\alpha} \rho \kappa \eta \varsigma) »$.

${ }^{66} 68$ B 293 = Stob. IV 48.10: «Quienes encuentran placer en las desgracias de los vecinos no se dan cuenta de que los avatares del azar son comunes a todos y carecen de alegría propia».

${ }^{67}$ Sobre el azar en Demócrito, cf. p. ej. Vlastos 1945, pp. 578-592, Alfieri 1953, pp. 96 ss., Edmunds 1972, pp. 342-357, Taylor 1999, pp. 188 ss., Morel 2000, Conche 2005, pp. 11 24, Aravantinou 2005, pp. 30-49. 
las coincidencias con la doctrina atribuida al físico son más numerosas que las diferencias, lo que sigue haciendo de Demócrito el candidato más probable. Y segundo, porque estas diferencias pueden explicarse por las particularidades de la interpretación que el autor del papiro haría de las opiniones de Demócrito.

De hecho, Demócrito ha sido interpretado conforme a los prejuicios de los autores que se acercaban a sus doctrinas, siendo un ejemplo de ello la propia concepción del azar. Según unos ${ }^{68}$, Demócrito pensaba que nada sucede por efecto del azar, mientras que para otros ${ }^{69}$, habría defendido que todas las cosas son y se generan por obra del azar. Los primeros, Aristóteles y sus seguidores, llegaban a esa conclusión porque consideraban el azar como una causa accidental que concurre en las cosas que no suceden ni necesariamente ni la mayoría de las veces y que se hacen para algo y son objeto de elección, y esa noción de azar no se corresponde con el mundo democríteo, en el que todo tiene una causa necesaria determinada y carente de fines. Los segundos, Epicuro y sus seguidores, llegaban a la conclusión opuesta, porque atribuían a Demócrito una concepción del azar vinculada a la interacción necesaria de los átomos, a la cual está sujeto todo lo existente ${ }^{70}$. Ello supondría un determinismo que incluiría a la propia conducta humana, que estaría constreñida al movimiento necesario de los átomos del alma, en el que no se daría la desviación que posibilitaría la libertad humana ${ }^{71}$.

${ }^{68}$ Aristóteles (Ph. II 4, 195b 36) y Simplicio (in Ph. 330.14).

69 Epicuro (Ep. III 133-4), Dionisio de Alejandría (ap. Eus. PE XIV $27.4=68$ B 118), Lactancio (Inst. I 2 = 68 A 70). Según Luria 2007, pp. 976, 982, Epicuro sería la fuente de Dionisio y de escritores cristianos como Lactancio.

70 Esto implicaría, de hecho, la negación del azar en Demócrito, entendido como causa inconstante y aleatoria, ajena a la voluntad humana. Así, por ejemplo, en su Epístola a Meneceo (134), Epicuro, exponiendo la postura del sabio frente al azar, dice que no cree que éste sea una causa «sin fundamento real», utilizando un adjetivo, $\alpha \beta \varepsilon ́ \beta \alpha 1 o \varsigma$, que es un claro eco del fr.

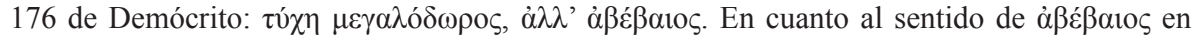
esta epístola de Epicuro, cf. Arrighetti $1973^{2}$, p. 544.

${ }^{71}$ Cf. también Epicur., Fr. 281 Us., Diog. Oen., Fr. 33 col. 2, Cic., ND I 26.73, Oenom. ap. Eus. PE VI 7.2 (fr. 14 M.): «Entre los sabios, ha sido eliminado de la vida humana el control de nuestra vida, ya sea que guste llamársele timón, apoyo o fundamento, que nosotros consideramos soberano de lo que más necesitamos. Al menos Demócrito, si no me equivoco, y Crisipo, pretenden demostrar que lo más bello entre las cosas humanas es, para el primero, la esclavitud, y para el segundo, la semi-esclavitud». 
Del mismo modo, cuando el autor del papiro dice que el físico cree que el azar está implicado en todo lo que daña al hombre, bien puede estar atribuyendo al físico una concepción determinista del azar, según la cual éste sea una causa necesaria de los males que acaecen al hombre, de igual manera (aunque esto lo no diga) que lo sería también de los bienes. Y esto, aunque no concuerda con la concepción democrítea del azar, sí es una interpretación posible de ésta, como acabamos de ver.

Por otra parte, acudir al azar como causa revela la negación de la existencia de causas finales y explica que no se quiera concebir el mal como efecto de la voluntad de los dioses, pues implicaría una intención, un propósito, un fin. $Y$ en ese sentido el físico sí coincidiría plenamente con Demócrito, quien no sólo prescinde de las causas finales, sino que exonera a los dioses de responsabilidad en el mal humano ${ }^{72}$.

En cuanto a la atribución al físico de una noción de azar no sujeto al dominio del orden cósmico, bien puede aplicarse también a Demócrito, si tenemos en cuenta la propia concepción del orden cósmico del autor del papiro. Para éste, dicho orden depende exclusivamente de Zeus, quien dispone como garante de éste a la Justicia y a sus servidoras, las Erinis. En cambio, para Demócrito, el universo no está sujeto a la inteligencia o providencia de ningún dios ${ }^{73}$, sino sólo al orden surgido de la combinación azarosa de los átomos entre sí. Es lógico que esta noción del universo fuera interpretada por el autor del papiro como un estado de cosas en el que el azar sería la fuerza dominante, y ante el cual el orden cósmico, entendido como el resultado de la acción de un dios supremo, fuera impotente.

\section{Conclusiones}

En conclusión, creo haber mostrado que Ferrari tiene razón, primero, en contraponer la opinión del físico con la del autor del papiro, y, segundo, en identificar con un alto grado de probabilidad a dicho físico con Demócrito. Las razones que nos llevan a esa conclusión son, en resumen, las siguientes:

$1^{\mathrm{a}}$. Otros candidatos posibles para ser identificados con el físico, como Heráclito, Anaxágoras, Pródico o Empédocles son menos probables, porque

7268 B $175=$ Stob. II 9.4.

7367 A $22=$ Aët. II 3.2, 68 A $70=$ Lact., Inst. I 2, Nemes., Nat. Hom. 44, p. 347 Matth. 
sus doctrinas sobre la plegaria o sobre la concepción del azar como responsable del mal en el mundo concuerdan menos con las del físico que la de Demócrito.

$2^{\mathrm{a}}$. Demócrito comparte con el físico una concepción muy similar de la plegaria, pues elude usarla como mecanismo de apaciguamiento o de petición de favores a los dioses, y la considera inútil por la misma razón: atribuye a los dioses un poder para satisfacerla que no les corresponde, ya que los dioses no son los causantes del mal.

$3^{\mathrm{a}}$. Demócrito comparte con el físico una actitud religiosa común, caracterizada por la tendencia a racionalizar el papel tradicional de los dioses mediante la atribución de sus acciones a causas naturales.

$4^{\mathrm{a}}$. Demócrito hace también del azar causa del mal humano, aunque no en todos los casos. Esta diferencia con la opinión atribuida al físico puede explicarse por la interpretación que el autor del papiro hace de la doctrina de Demócrito, atribuyéndole una concepción del azar como causa de todos los males que acaecen al hombre, fundada en la creencia de que para Demócrito la interacción azarosa de los átomos es causa de todas las cosas.

$5^{\mathrm{a}}$. La atribución al físico de una noción de azar no sujeto al dominio del orden cósmico es compatible con la doctrina de Demócrito de que el universo no está sujeto a la providencia de ningún dios, sino sólo al orden surgido de la combinación azarosa de los átomos. Esta doctrina pudo interpretarse por el autor del papiro en el sentido atribuido al físico, dada la diferente concepción de dicho orden sostenida por el autor.

\section{BIBLIOGRAFÍA}

Adomenas, M. 1999: «Heraclitus on Religion», Phronesis 44, pp. 87-113.

Alfieri, V. E. 1953: Atomos Idea. L'Origine del concetto dell'atomo nel pensiero greco, Florencia.

Aravantinou, A. 2005: «Necessity and Chance in Democritus' Cosmology» en AA.VV., Týkhe - Anánke. Hasard et nécessité dans la philosophie grecque, Atenas, pp. 30-49.

Arrighetti, G. 1973²: Epicuro. Opere, Turín.

Babut, D. 1975: «Héraclite et la religion populaire (Frag. 14, 69, 68, 15 et 5)», REA 77, pp. 27-62.

Bailey, C. 1928: The Greek Atomists and Epicurus, Oxford.

Bernabé, A. 2004: Textos órficos y filosofía presocrática, Madrid.

Bernabé, A. 2007: Poetae Epici Graeci testimonia et fragmenta, II 3, Berlín-N. York. 
Bernabé, A. (en prensa): «Apuntes sobre la col. IV del Papiro de Derveni», Actas del XIII Congreso Español de Estudios Clásicos (Logroño, 18 al 22 de julio de 2011). Bollack, J. y Wismann, H. 1972: Héraclite ou la séparation, París.

Burkert, W. 2010: «How to Learn about Souls. The Derveni Papyrus and Democritus», The Center for Hellenic Studies. Proceedings of the Derveni Papyrus Conference, July, 2008: <http://chs.harvard.edu/wb/1/wo/QbAjaa5U6XRkaTrN32CXYM/0.1> (20/07/2012)

Burkert, W. 2011: «The Derveni Papyrus on Heraclitus (col. IV)», en Herrero de Jáuregui, M., Jiménez San Cristóbal, A. I., Luján, E. R., Martín, R., Santamaría, M. A. y Torallas Tovar, S. (eds.), Tracing Orpheus. Studies of Orphic Fragments in honour of Alberto Bernabé, Berlín-Boston, pp. 361-364.

Conche, M. 1986: Héraclite. Fragments, París.

Conche, M. 2005: «La métaphysique du hasard» en AA.VV., Týkhe - Anánke. Hasard et nécessité dans la philosophie grecque, Atenas, Acaémie d'Athènes, pp. 11-24.

Curd, P. 2007: Anaxagoras of Clazomenae: Fragments and Testimonia. A Text and Translation with Notes and Essays, Toronto.

Diels, H. y Kranz, W. $1960^{10}$ : Die Fragmente der Vorsokratiker, 2. Band, Berlín.

Edmunds, L. 1972: «Necessity, Chance, and Freedom in the Early Atomists», Phoenix 26, pp. 342-357.

Eisenberger, H. 1970: «Demokrits Vorstellung vom Sein und Wirken der Gotter», RhM 113, p. 141-158.

Ferrari, F. 2010: «Democrito a Derveni? PDerv. col. 4, 1-6», PP 65, pp. 137-148.

Ferrari, F. 2011a: «Frustoli erranti. Per una ricostruzione di P. Derveni coll. I-III», en Papiri Filosofici. Miscellanea di Studi, VI, Studi e testi per il corpus dei papiri filosofici greci e latini, Florencia, pp. 39-52.

Ferrari, F. 2011b: «Eraclito e i Persiani nel Papiro di Derveni (col. IV 10-14)», en Herrero de Jáuregui, M., Jiménez San Cristóbal, A. I., Luján, E. R., Martín, R., Santamaría, M. A. y Torallas Tovar, S. (eds.), Tracing Orpheus. Studies of Orphic Fragments in honour of Alberto Bernabé, Berlín-Boston, pp. 365-370.

García Calvo, A. 1985: Razón común, Madrid.

Gutas D. (ed.) 2010: Theophrastus On first Principles: (known as his Metaphysics): Greek text and medieval Arabic translation, Leiden-Boston.

Guthrie, W. K. C. 1986: Historia de la filosofía griega, trad. esp., vol. II, Madrid $(=1965)$.

Henrichs, A., 1975: «Two Doxographical Notes: Democritus and Prodicus on Religion», HSCPh 79, pp. 93-123.

Jaeger, W. 1952: La teología de los primeros filósofos griegos, trad. esp., México D. F. $(=1947)$.

Janko, R. 2001: «The Derveni Papyrus («Diagoras of Melos, Apopyrgizontes Logoi?»): A New Translation», CPh 96, 1, pp. 1-32. 
Janko, R. 2008: «Reconstructing (again) the Opening of the Derveni Papyrus», $Z P E$ 166 , pp. 37-51.

Kahn, C. H. 1979: The Art and Thought of Heraclitus, Cambridge.

Kouremenos, T., Parássoglou, G. M. y Tsantsanoglou, K. 2006: The Derveni Papyrus, Florencia.

Laks, A. y Most, G. W. (eds.) 2002: Théophraste. Métaphysique, París.

Lanza, D. 1966: Anassagora. Testimonianze e frammenti, Florencia.

Lebedev, A. V. 1989: «Heraclitus in P. Derveni», ZPE 79, pp. 39-47.

Luria, S. 2007: Democrito. Raccolta dei frammenti, interpretazione e commentario di Salomon Luria, trad. it., Milán.

Marcovich, M. 1968: Heraclitus, Mérida (Venezuela).

McGibbon, D. 1965: «The Religious Thought of Democritus», Hermes 93, pp. 385397.

Megino, C. 2012: « El papel del orden y del azar en la col. IV del Papiro de Derveni», en Casadesús, F., Pons, D., Genovés, R. y Aparicio, C. (eds.), Una mirada actual a la filosofía griega, Ponencias del II Congreso Internacional de Filosofía Griega de la Sociedad Ibérica de Filosofía Griega, Madrid-Palma de Mallorca, pp. 781-790.

Mondolfo, R. 1971²: Heráclito. Textos y problemas de su interpretación, México D. F.

Morel, P. M., Atome et nécessité: Démocrite, Epicure, Lucrèce, París, 2000.

Most, G. W. 1988: «Heraclitus D-K 22B124 in Theophrastus' Metaphysics», en Fortenbaugh, W. W. y Sharples, R. W. (eds.), Theophrastean Studies in Natural Science, Physics and Metaphysics, Ethics, Religion and Rhetoric, New Brunswick-Oxford.

Parássoglou, G. M. y Tsantsanoglou, K. 1988: «Heraclitus in the Derveni Papyrus», en Brancacci, A. et alii (eds.), Aristoxenica, Menandrea, Fragmenta Philosophica, Florencia, pp. 125-130.

Robinson, T. M. 1987: Heraclitus. Fragments, Toronto.

Taylor, C. C. W. 1999: The Atomists: Leucippus and Democritus, Toronto.

Vlastos, G. 1945: «Ethics and Physics in Democritus», The Philosophical Review 54, pp. 578-592.

Fecha de recepción de la primera versión del artículo: 23/07/2012

Fecha de aceptación: 31/01/2013

Fecha de recepción de la versión definitiva: 06/4/2013 